\section{INSECT METAMORPHOSIS *}

F VERYBODY, whether learned or unlearned, is aware that I insects undergo changes in their shapes and habits. Great numbers of popular works on natural history have made the description of these changes or metamorphoses familiar to the description and Newport, Dugés, Heroldt, Fabre, and those British public; and Newport, Duges, Herold, Fames are household words entomologists and naturalists whose names are household word amongst us, have informed the scientific world upon the anatomical and minute changes of structure which accompany the wonderful varieties in form and in method of life. The array of facts is enormous, and yet, with all this vast amount of sterling knowledge to build upon, very little progress has been made towards recognising the cause and meaning of metamorphosis in biology-in the science of life. The facts and details of the subject have been accumulating, but the nature of its philosophy has been studied by very few naturalists, and it is only of late years that Lubbock and Fritz Miiller, and a few others, have been stimulated by the light of the theory of evolution to ex- amine into it. Believing that the subject is increasing in interest, and that its consideration bears upon some of the most im portant theories respecting life, it is proposed to devote this lecportant to a description of the different kinds of metamorphoses in insects, and to a consideration of the biological meaning of the phenomena.

Let me recall to your recollection two instances of what may be called perfect and complete metamorphoses. When the tenderest cabbages are growing in the early summer, a number of very small caterpillars or larve may be seen upon the plants, devouring them in a regular and systematic manner. A voiding the leaf-veins as indigestible, they nibble the juicy leaf, and consume daily more than their own weight. These pests of the gardener have small heads and ends, and the body is greenish and striped with yellow bands, being at the same time hairy. At first very small in size, the caterpillars do not attract much At fiving for a few days, they hide attention, and esperialled and ill. After a short time, the caterpillar in retreat bends its back violently, and

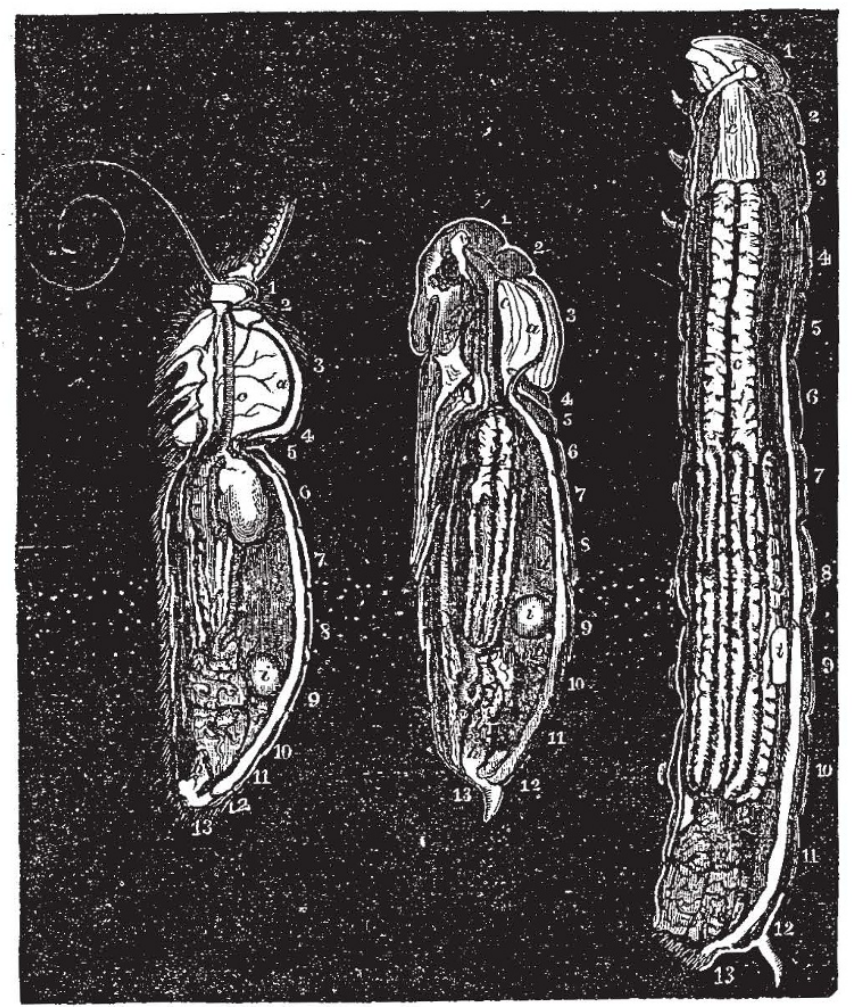

FIG. I.-Metamorphosis of Tortoise-shell Butterfly.

splits the skin of one of the rings or segments of the part nearest the head, then a vigorous struggle enables the legs and the head to be withdrawn through the crack, and the larva is noticed to have attained a new skin within the old one. It crawls on to its favourite plant and makes up for lost time, grows rapidly, and really may be said to live to eat. It cares not for its fellows, nor for any other leaves; it is content with its own cabbage, and has no ambition and no desire to quarrel or to move away. During growth the powers of mastication and of digestion increase, but they are checked several times by the larva having to pass a period of quietude whilst a new skin is finished under the old, and whilst this is cast off. These skin sheddings have a definite relation to the increasing size of the insect, but they are not simple changes of skin because the old one has become too tight for its rapidly growing possessor. They accompany certain important changes within the insect, and not only is the outside skin shed, but the mucous membrane of the digestive organs

* A Lecture delivered before the British Association, $187_{-1}$ by Prof Duncan, F.R.S. and of the air tubes which enable the creature to breathe, suffer also. They are really important elements in the metamorphosis, which term includes the sum of the changes of shape, habit, and instinct.

When full growth has been attained, the caterpillar crawls from its cabbage and wanders restlessly about, even to considerable distances, in search of a dry sheltered spot. After having discovered such a locality, it fills up the space between its hind legs with silk, and attaches this part of the body to the wood or stone, as the case may be. The larva then hangs head downwards, and forthwith begins to bend its head backwards, upwards, and then from side to side, until, after a little practice, it is enabled to touch the solid substance to which it is hanging on either side of its body. Then some silk is secreted, and by applying the mouth to the spots touched one after the other, fine sling of silk thread binds the insect down and prevents it from being swaycd to and fro by the wind. This is the last act of the larva which shows any evidence of wrill. Then it begins to look shrivelled, shorter than before, and broader behind the 
head, and after a time the skin splits, and is shed with greater or less wriggling. A sticky, varnish-looking moisture covers the very different-looking thing which now presents itself, and dries rapidly, and forms a case over the skin of the "pupa" beneath. The alterations within and without the insect at this time, that is to say, during three or four days after leaving the cabbage, are carried out with great rapidity, and the future butterfly is well foreshadowed at this period in the structure of the chrysalis or pupa. Hanging as a chrysalis or pupa in a perfectly immobile condition, neither seeing, hearing, nor tasting, and losing very little weight from the exhalation of its moisture, the insect lives on for many months, and until spring has nearly ended. Then the dark case splits, and a tender white butterfly crawls forth, and, under the influence of warmth and the sun, becomes dry,

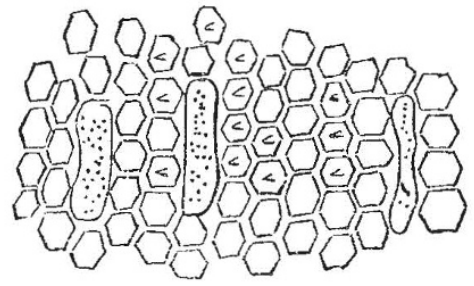

FIG. s.-Esophageal Epithelium.

strctches, and unfolds its crumpled-up wings, walks feebly upon long legs, trails a short body, moves a curious flexible trunk in front of its head, the result of the modification of its former jaws, and takes to flight. The common white butterfly, whose solitary flight is so zigzag and wandering, and whose flight in company is so tumultuous, ascending and vibrating, lives for love. It has a soul above cabbages, and rarely condescends even to sip or suck the daintiest nectar from flowers. After a longer or shorter existence, it begins to lay eggs, and places them in the immediate

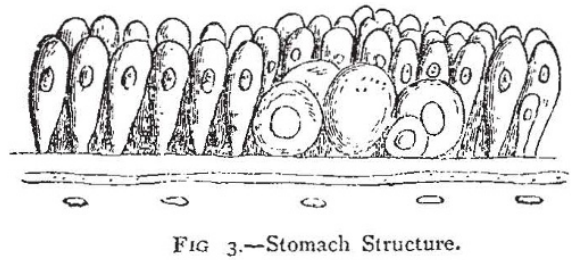

neighbourhood of the favourite food of the larva, which are to come from them.

Another familiar example of perfect metamorphosis may be studied in the instance of one of the false wasps, Odynerus parietum. This small wasp-like insect may be seen on the other side of the Channel in great companies on lucern and clover when in full flower. It is a solitary kind, and the male and female care nothing for their companions, who rush and tumble over, in, and about the flowers, sucking their sweetness, and squabbling

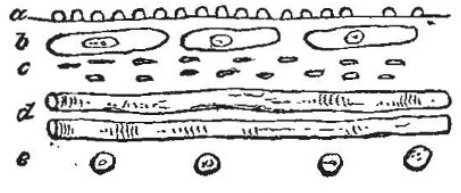

Fig. 4-Pylorus.

and flying for the freshest corollas. Day after day this buzzing busy crowd may be seen leading a life of happy enjoyment, feeding, playing, and flirting; but after a while an unusual excitement is noticed amongst a large number of the insects. These extend their flight beyond the favourite field, and seek the neighbourhood of sandy clayey banks close by. They may be observed digging their heads into the sand with great assiduity, and pulling out sand grains, and gradually forming a hole. Each wasp works independently of its neighbour. As soon as the hole is large enough to admit the wasp's body, the legs remove, by a process of brushing, the particles loosened by the jaws. After a short time the wasp will be found to have made a tunnel, and the constant out-pour of sand and clay indicates that excavation is still proceeding out of sight.

Soon the Odynerus perfects two or three chambers deep in the bank and opening into the tunnel. She (for it is the female who does the work) carefully pounds the insides of the cavities and removes all roughness from them, and leaves them as commodious hollows, water-tight, and not likely to fall in. This is not all. On coming back into the light, the wasp seizes cylindrical pieces of earth, and moulds them more or less into shape with her jaws, and places them in front of each other, and side by side, so as to form a hollow tube, which sticks out from the bank and opens into the tunnel. The free end of this ante-chamber is left open, and the pieces of which the whole is formed are gummed together and pressed. The tube is ex-

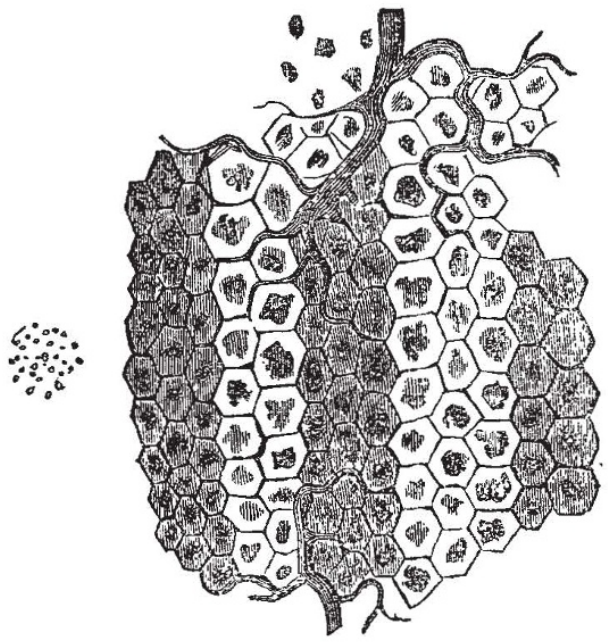

F1G. 5-Stomach Structure of Pitpa.

tremely fragile, and the pieces of it are not in cortact cverywhere. Nevertheless, the Odyneruts passes along it readily enough, but no other insect of its size can do so. All this work is carried on whilst the wasp appears to be in an intense state of excitement, and when it is completed the insect flies off to the flowers again. But not to return to its former habits. On the contrary, the purposeless tumbling about of flowers, and the occasional sip of nectar, are forgotten, and the flighty little vegetarian becomes a ferocious and ardent huntress of prey. She seeks the small larvæe of a species of weevil which abounds about the plants, and seizing one, digs her sting into it, so that a weak venom is introduced close to the nervous system of the victim. The larva is paralysed

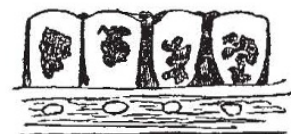

Fıg. 6.-Stomach Structure of Imago.

at once, but not killed ; on the contrary, it remains motionless, but lives. She then flies off with her prey to the bank, enters the tubular ante-chamber, traverses the tunnel, and reaches one of the chambers. Here she deposits her insensible victim, and lays one egg close to it. Returning again to the field, she seizes another larva, stings it, and carries it off to deposit it close to the first. This procedure is repeated as many as thirty times, and the chamber becomes full of insensible weevil larvæ and one Odynerus egg. The other chambers are filled in the same manner, and an egg is laid in each. Then the wasp comes out of the tunnel for the last time, breaks down the tubular ante-chamber, so as to hide the entrance to the tynnel and chambers, flies off, and dies. She never sees her offspring, for which she, a vegetarian, has provided animal food in abundance. 
The egg is soon hatched in each chamber, and a small, legless, and extremely delicatelarva crawls forth, and seizes upon the victim close to it. So tender is the Jarva that the least roughness of the sides of the chamber would destroy it, and the least struggle on the part of the poisoned veevil grubs would kill it; but all this has been made safe, and the little thing eats into its living prey, and when one is finished it attacks amother, until all are eaten up. This is the life of the lasva. It is incapable of walking any distance, and simply leads a life of gormandising on the flesh and juices of weevil grabs. It never emerges from the chamber, and when it has no more to eat, spins a cocoon of silk around itself, and sleeps therein during the late autumn, the winter, and until the spring. Then a change in form ensues, and a pupa, which greatly resembles the perfect insect, appears under the skin which is shed. In the course of a few weeks the perfect false wasp escapes from the pupa skin, digs its way into the world, and emerges to enjoy the destiny already described.

Many other false wasps which belong to the same group of insects as this Odyncrus have a somewhat corresponding life cycle, and choose many curious kinds of prey, but the formation of the safeguard of "the tubular ante-chamber places this kind in advance of all others. It is then an example of very perfect metamorphosis with high instinct, and, like in all other instances of what is termed perfect metamorphosis, there is an intermediate stage of a quiescent pupa between that of the larva and imago, both of which are able to lead independent and distinct kinds of lives, and to take food.

Considered as isolated examples, these two instances of metamorphosis are perfectly inexplicable, except on the theory that the successive changes-shape, structure, and habitwere especially given to the species at their origin, by special creation. When, however, the nature of the very different metamorphoses of other insects, which closely resemble these in structure, is examined into, this view does not give entire satisfaction, and an uncomfortable feeling arises, that we with finite understandings are tying down the operations and mysterious ways of Omnipotence to our own limited standard.

But before proceeding any further, it is necessary that the nature of some of the structural alterations which occur during metamorphos.s should be stated. By so doing a distinction can be appreciated between ordinary continuous growth or progressive development, and the changes which occur during the perfect metamorphosis of an insect. Consider shortly the nature of the chance of outside form. A young larva of a butterfly or moth has a head which is not separated by a neck from the long body, and the whole is divided more or less distinctly into rings or segments. The three segments next to the head form the chest and support the true legs, and are succeeded by nine others belonging to the body or abdomen. There are then thirteen in all. The body segments are nearly equal, but the last is the smallest, and it, together with some of the other rings, supporis what are termed false legs or claspers. They are continuations of the skin, and do not exist in all larvæ of butterflies and moths ; and, although they are extremely useful in enabling the insect to hold on and to crawl, they disappear in the pupa state with the last skin-shedding. Thus there is the head segment, and three chest segments, and nine body segments, and on the side of each of these, excepting the head, is a point, which usually marks an opening where air tubes or trachee enter the body to ramify over the whole of the internal structures. When within the egg, and before it was perfectly formed, the head of the larva consisted of at least four separate pieces, but these united and coalesced in one before birth. None were destroyed, but the edges of the separate portions fused together. A corresponding fusion and blending of certain of the chest and body segments occurs during metamorphosis, and there is neither a destruction nor new creation of parts to produce the extraordinary differcnce between the long body of a caterpillar, the short swathed figure of the pupa, and the great chest and small abdomen of the butterfly. The same anatomical elements are present, but they are more or less modified.

The first skin sheddings of the caterpillar do not add to or alter its segments, but the last skin shedding which occurs during a period of immense internal change exposes the pupa or chrysalis to view, and all the characteristics of the skin of the larva are lost. On commencing this last skin shedding, the chest segments, 2, 3, and 4 (Fig. 1) of the caterpillar, increase in size, and the insect really soon begins to shorten. The small Tortoise-shell butterfly larva is thus suspended, with its skin on, for some ten or twenty hours before the chrysalis is revealed.
During this time, the $2,3,4$, and 5 segments become much enlarged and curved downwards by the action of the muscles of their under surface, which are repeatedly contracted and expanded slowly. The skin bursts, and the insect then exerts itself to the utmost to extend the fissure along the segments of the body, and gradually draws out its an!enne, or feelers, and its weak but long legs, and immature wings, all of which have been maturing beneath the old skin, and are covered with an extremely delicate tissue. The false legs drop off with the old skin, and the pupa hangs in this moist and curious condition for a few minutes. Then it makes a few powerful efforts, and contracts and expands itself to the utmost by taking in air through its air tubes and forcing it out again by bringing the segments closer together. The result is to contract the body segments along their under surface, and to diminish their length generally. The front margin of one segment is drawn up within the hinder edge of the one in front, and especially in the case of the fifth and sixth segments. This contraction persists, and in the neighbour. hood of the fifth is sufficient to initiate the small waist-like circular division between the chest and the body, which becomes more distinct in the imago than in the pupa. Atroplyy and shortening of the fifth and sixth segments occur; and there are correspond. ing changes in the first and second segments, so as to commence a neck. A gelatinous viscid fluid is secreted by the pupa, and it covers all its delicate external skin, and by hardening, agglutinates all beneath. After a while the true skin of the pupa, is found separated by air from the dark pupa case outside.

After the escape of the imago from the pupa case, if its wings be removed, and its head, chest, and body be examined, the distinction between the number of its segments and those of the full-gromn larva will be readily appreciated. The nine body-rings of the caterpillar exist, but are much modified. The two terminal are drawn up inside the body, and the first segment has joined itself to the last chest-piece. The shortening is very great, whilst the enlargement of the rings which support the wings-namely, the third and fourth-with much consolidation and fusion of them, does not compensate for it. As may be supposed, the shortening of the internal organs must be extraordinary, and as a matter of fact the nervous cord is shortened, its ganglia are concentrated, and the digestive apparatus is diminished in length in a remarkable manner.

The changes in the digestive organs keep pare with those of the skin and general shape, and may be briefly describe as follows:- When a caterpillar nips off a piece of a leaf with its jaws, the morsel is passed into the gullet, which is a short tube leading to the stomach. The gullet is composed of a mucous coat which is internal, and of a muscular covering which is external. The mucous coat consists of a delicate structureless membrane, which is continuous with a corresponding tissue in the mouth in front and in the stomach behind. It is called the basement membrane, and that of the gullet is folded longways, when it is empty. When the gullet is crammed with food, the folds are obliterated and the membrane is stretched. All the irside of this membrane is covered with a layer of delicate hexagonal cells, which are very small and thin, and consist of a plain cell wall and transparent fluid contents (Fig. 2). They cover the basement tissue like a pavement, and the morsel of food conies in contact with them, and they absorb and transmit any vegetable liquids which may escape from the cells of the leaf. Between the hexagonal pavement cells here and there are oval depressions filled with granular mucus. The basement tissue is slightly depressed in these spots, and these crypts secrete a fluid which acts like the salivary glands of man upon starchy and sugary fluids. Amongst the hexagonal cells are others which have their upper surface produced into a short tooth-like projection, that foreshadows a remarkable structure in the perfect insect. Outside the basement membrane is a single row of hoop-shaped muscular fibres. They are broad and nucleated, but not striated. Each fibre encircles the gullet, and tends, with the simultaneous contraction of its fellows, to diminish the calibre of the tube, and to throw it into longitudinal folds. Their passive dilatation, on the contrary, permits the gullet to become distended. They have, however, the peculiarity so common in the circular muscular fibres of all animals, of contracting one after the other in series, and of dilating or expanding in the same rhythmical manner. The result of this progressive contraction is to force the contents of the gullet in the direction of the stomach. The alterations of contraction and the expansion permit the layer of muscular fibres, which is outside the circular set, and whose direction is longitudinal, to pull up and shorten the canal. The long fibres are 
attached to a ring behind the mouth, and around the commencement of the gullet, and they are continued down the tube to the stomach. They are closely packed, and are very distinct. When the gullet is shortened by their contraction, any food in it is brought nearer the opening into the stomach, and then it is forced into that organ by the progressive contractions of the circular fibres. The piece of leaf is lubricated by the granular mucus of the crypts, and is squeezed by the contraction of the circular fibres. Much of the contents of the cells of the leaf is thus set free, and is absorbed by the mucous cells, and transmitted through the basement tissue to the blood, which permeates all the tissues more or less.

The stomach is large in comparison with the size of the larva, is cylindrical in shape, and does not taper gradually into the gullet in front and the intestine behind. The calibre is many times greater than that of the rest of the digestive canal. Like the gullet, a mucous layer, a basement membrane, and two sets of muscular fibres, enter into its composition. But the mucous membrane differs in every particular, except in the structureless basement membrane. The basement membrane is densely covered internally by an aggregation of large cells of two kinds, and the more active the larva may be in its eating, the more numerous and larger are these cells. One kind is elongate, and narrow at the base, where there is an attachment to the membrane, and rounded at the free end ( $\mathrm{Fig}$. 3). They are thus more or less club-shaped, and they are formed by a very delicate cell wall, a nucleus and more or less granular, coloured, and liquid cell contents. They are crowded together, and belong to what is called columnar epithelium. They become less bulky, thinner, and crooked, if the caterpillar is starved, and just before the skin-sheddings also. Another kind is represented by large globular cells, which are fewer in number compared to the others. They are composed of a very delicate cell wall, of nuclei, and liquid contents, and they burst in the ordinary process of digestion, and appear to supply a gastric juice. The columnar cells, on the contrary, absorb nutritious matters, and transmit them through the basement tissue. These huge cells are very remarkable, and all degenerate, and greater part are cast off during skin-sheddings. A layer of circular or hoop-shaped muscular fibres is found outside the basement membrane, and whilst those of the fore part of the stomach are so closely applied to each other, side by side, as to form a continuous circular muscular coat, those of the nether parts of the organ are wider apart, but at the termination of the canal in the intestine they are again concentrated, and not simply in one row, but in many, so as to form a dense circular muscle or sphincter. The longitudinal fibres are outside these, and are continuous in front with those of the gullet, and they end in the tissue, which connects the dense circular fibres of the sphincter together. The large cells of the inner coat of the stomach are not found on the basement membrane which covers the thick sphincter, and they cease suddenly a short distance in front of it.

This part of the stomach is evidently in very constant and somewhat violent movement, for the, use of the dense mass of circular fibres is to compress and crush the food in its passage to the intestine; consequently, a cellular layer exists on the basement, which is suited to bear pressure. The cells of this part resemble to a great extent those of the gullet; they are flat, hexagonal, and pavementlike, but a great number of them have very decided tooth-like projections on their free surface $(a$, Fig. 4$)$. These projections occur in numerous circular series, and they are sufficiently prominent to wound a delicate vegetable cell passing over them, and submitting to the pressure induced by the contraction of the circular fibres. It is evident that if the muscular contraction be great, and the cells of the leaf rather hard, these hexagonal tooth-bearers will suffer from much and perhaps destructive compression.

But a very interesting structure is superadded to this part of the digestive system in order to prevent such an accident to the delicate mucous membrane. There is a layer of very large flattish cells beneath the basement membrane and between it and the circular fibres. Each of these cells $(b)$ contains much fluid within a very visible cell-bag, and there are the usual nuclei. They are not quitein opposition laterally, and they rest upon an expansion of the muscular fibres, some granular fluid and nuclei intervening $(c)$. Their office is to act as cushions beneath the immediate seat of pressure, and where the circular fibres are the strongest, there they are best developed. This arrangement of fibres, cushion cells, basement membrane, and delicate tooth-like projections, is continued to the extreme end of the stomach. There the circular sphincter muscle exists, and the basement is folded more or less ongitudinally, so as 'to admit of the calibre of the canal being extended and contracted to the utmost. The cell teeth are found here in angular series, and there is one circular row of large ones. Microscopic examination of the dense mass of circular fibres reveals that the fibres are separate, stout, and that some of them possess a structureless investing membrane $(d)$. The longitudinal muscles of the stomach, which are extremely long and close together, end by forming one or even three processes, which are united to the circular fibres, and the corresponding fibres of the intestines take their origin in this sphincter. Many nerves and air-tubes supply this part, which ends in an intestine of moderate length, and which time will not permit me to consider.

These structures are all developed in exact relation with the gormandising habits and the nature of the food of the cabbage-eating larvæ. The pieces of raw vegetable consist of cells with tolerably stout walls, and these have to be broken into before any nutritious matter can be let out to be digested, and the growth of the insect is so rapid that the quantity of food swallowed and passed along the stomach is very great.

This active stomach has periods of rest during the skin-shedding, when the cells of its mucous coat are cast off and replaced by new ones. The day comes at last when the caterpillar loses its love for cabbage and is to get no more, and then, ere it hangs pendent before the alterations in the size of the segments commence, changes may be noticed to have begun in the anatomy just described, changes which might take place from disuse. The stomach is, comparatively speaking, empty of food, the club-shaped cells are smaller and less round, and the globular cells are broken up. The muscular fibres appear thinner, wider apart, and more transparent. Immediately after the agglutination of the outside of the pupa occurs, sensible changes proceed in the digestive canal, and very rapidly. By the fifth day the whole canal has become shorter, the gullet has become thread-like and longer than in the caterpillar. The stomach is not half the length or one-third of the breadth of its former condition, and the intestine is longer than before. A general atrophy of all the layers of muscular fibre exists, and the dense muscular sphincter of the stomach with its peculiar fibres has been absorbed and replaced by simple, separate, and delicate circular muscles. The longitudinal fibres are wide apart, and very transparent. The longitudinal folds of the gullet have disappeared with the mucous crypts, and the basement membrane is covered with a granular fluid, in which the remains of the old hexagonal cells float. A mass of brokerr-down, club-shaped globular cells occupies the small stomach, and a totally different arrangement covers the basement. Cells packed closely together here and there, and separated by lines of granules, indicate that a new kind of mucous coat is being developed. These cells assume the hexagonal shape, are moderately tall, and contain a few granules, and they extend over the place of the toothed cells at the sphincter, and join the cells of the intestine (Fig 5). The toothed cells have disappeared, and the cushion cells of the region of the sphincter also. All these structures are remarkably delicate and difficult to manipulate, and it may be remembered that they are not performing any function whatever.

When the imago escapes from its hard pupa case, and when it has completed its metamorphoses, the digestive canal presents further modifications, which are brought about, however, during the imprisonment. The gullet is longer, and has a sac-like crop projecting from it; the stomach is narrower, and the intestine is longer. All the muscular fibres are extremely delicate, and there are no new arrangements of them. The basement membrane of the gullet is developed on one side into a bag-shaped tissue, and the whole of it is covered by extremely delicate cells, most of which have a long hair-like process sticking up from them, which was foreshadowed by the tooth-like projection of the larva state. The stomach cells have increased in height, and contain granules, but they resemble those of the pupa until the food is taken; then the cells increase in size, and many are set free in a globular form, and there is not a want of likeness between some of them and those of the larva (Fig. 6). This long gullet, crop, and tubular stomach, so flaccid from want of strong muscles, is admirably adapled for the peculiar food of the perfect insect. The sugary fluids of flowers require no crushing and rasping, and not much digestion-so the hairs of the gullet-cells assist in the passage of the syrup down the canal, and the gentle pressure of the delicate muscles of the stomach suffices for its purpose.

To say the least, these are wonderful changes in the same anatomical elements, and they indicate that metamorphosis in- 
cludes modifications the result of disuse and alterations which bear a prospective relation to the future wants of the altered insect form.

It appears at first sight that this separation into different stages of life is necessary for the insect, and that it must have a time devoted to eating, digesting, and assimilating, a quiet condition devoted to internal changes, and a stage where reproduction can be carried on. But this generalisation fails when it is remembered that some larvæe eat and reproduce, and some imagos reproduce and lead bloodthirsty lives also. It is important to recognise the distinction already hinted at. The growth of the young embryo larva within the egg, and that of the escaped and skinshedding larva, is progressive, but the descriptions given of the changes in the shape and in the anatomy of the digestive organs of the pupa and imago, prove that they do not depend upon simple progression from elementary condition to complexity. The changes of structure belong to a different order of things to the simple growth of the larva's tissues; they appear to be superadded.

(To be continued.)

\section{NOTES}

THE Medals in the gift of the Royal Society have this year been awarded as follows:-The Copley Medal has been awarded to Professor Friedrich Wöhler, of Göttingen, For. Memb. R.S., for his numerous contributions to the Science of Chemistry, and more especially for his researches on the products of the decomposition of Cyanogen by Ammonia ; on the Derivatives of Uric Acid; on the Benzoyl Series ; on Boron, Silicon, and their compounds; on Titanium, and on Meteoric Stones. A Royal Medal has been awarded to Professor Thomas Anderson, M.D., for his investigations on the Organic Bases of Dippell's Animal Oil ; on Codeine; on the Crystallised Constituents of Opium ; on Piverin and on Papaverin; and for his researches in Physiological and Agricultural Chemistry. A Royal Medal has been awarded to Mr. Henry John Carter, F.R.S., for his long-continued and valuable researches in Zoology, and more especially for his inquiries into the Natural History of the Spongiadx. Ine Rumford Medal, awarded every two years, has been awarded "to Anders! Jonas Angström, For. Memb. R.S., for his Researches on Spectral Analysis.

THE annual meeting of the Fellows of the Royal Society, for the clection of officers and Council for the ensuing year, will be held, as usual, on the 3 oth inst. As we have before announced, Dr. Sharpey, after a long period of service as secretary, resigns his functions, which have been of such great advantage to the Society, and by the performance of which he has earned the thanks and respect of ail men of science, Prof. Huxley being nominated by the council as his successor.

In the Boston Daily Adverliser for Saturday, Oct. 26, 1872, the conclusion of Prof. Tyndall's last lecture is thus reported :"There are three great theories which enable the human mind to open the secrets of nature-the theory of gravitation, the mechanical theory of heat, and the undulatory theory of light. These three pillars, as far as the human intellect is concerned, support the universe. To whom are we indebted for these discoveries? To men who had no practical ends in view, and who cared only for the truth. To-day, when there are so many temptations to young men to leave pure science for practical aims, it behoves us to look with sympathetic eyes upon the investigator who makes all this knowledge possible. I met on the steamship Russia a respected friend who ascribed the electric telegraph to 'a source to which I certainly should not have thought of referring it. It is the direct outcome of men who never made a shilling by it. Volta, Faraday, never made a shilling by it. All honour to the men who make these discoveries. Gauss and Weber, at the University of Göttingen, actually constructed a telegraph line from the physical cabinet to the observatory. Give all honour to the men who apply discoveries, but do not forget the men who make them. Many of you in this country have made fortunes, and have shown that you know how to apply them. Look with sympathetic eye upon the investigators. Give them opportunities. Do not overload them with other work. 'Cast your bread upon the waters,' and believe me 'it will return to you after many days.' My course among you is nearly over. I began it with some anxiety and end it with regret. It has been harder for me at times than I Thad expected, and I owe much to my assistants. I shall long and gratefully remember my reception on the occasion of my first lecture here. If $I$ am treated in the same manner elsewhere, I shall return to the old country full of content. During my stay here $I$ have heard 'the old country' mentioned again and again. You cannot abolish your antecedents. Out of England's loins you have come. Your ancestry is stamped upon your faces, your laws, your politics, and your characters. De Tocqueville, sympathising with democratic institutions, says, regarding England and America : "I refuse to regard these people as two; one is the outgrowth of the other." Atrocious ignorance of each other is at the bottom of all our differences. I trust that hereafter each nation will respect the individuality of the other; while thoroughly maintaining its own.' The lecture was listened to with great attention, and loudly applauded at the close. Every point made in behalf of the investigators, and upon our relations to the mother country, received loud approbation. Our report cannot do justice to Dr. Tyndall's earnestness in the latter portions of his lecture. It is to be hoped that some of our so-called 'practical men' may take to heart the lessons he has tried to teach them."

The late Prof. De Morgan, in a note to his article on Tables in the "English Cyclopredia," strongly expresses his regret that the British Museum did not purchase Dr. Hutton's valuable mathematical library, and, consequently, the first set of mathe. matical tables ever collected in England was dispersed. With a view to avert a similar break-up, we may inform our readers that at a very early date the mathematical collections of the late $\mathrm{Mr}$. Babbage must be disposed of. It is with reference to these that De Morgan, in the above-cited article, acknowledges his indebtedness ("large and rare collection of Tables"). Its excellence, however, is not confined to this special department only. We learn that catalogues will be issued in the course of a few days.

IN reference to the Swiney Lectureship, which we announcel recently as having become vacant, we venture to hope the post will not be thrown away on some one who is already well off, and has taken his place in life, but that it will be given to some young man who has shown himself well qualified for scientific research, and who may thus be enabled to devote his time to investigations which may lead to results of enduring value. Several eminent men have already held this lectureship, including, we believe, Dr. Carpenter.

Prof. WeIss, of the Vienna Observatory, has recently passed through London, on his return from a tour of inspection through the United States, where he has visited all the principal observatories, in order to collect materials for a report on the instruments demanded by modern science in a first-class observatory like that of Vienna, which is about to be removed and extended. It appears that the $26 \cdot$ inch object-glass ordered by the American Government, as soon as the completion of Mr. Newall's magnifcent instrument has established the feasibility of such an enorx.ous aperture, is already finished, and the mounting is in a forward state.

Silliman's Yournal for November mentions the death of the Rev. John B. Perry, Professor of Primordial Geology in Harvard College, and of Dr. John F. Frazer, Professor of Natural Philosophy and Chemistry in the University of Pennsylvania.

THe death is announced, in the Isle of Wight, on Friday last, of Dr. H. B. Leeson, F.R.S., for many years lecturer on chemis. try at St, Thomas's Hospital, 